\title{
Jefferson
}

Thomas Jefferson University

JHN Journal

8-1-2012

\section{Undergraduate Neurosurgical Learning Opportunities at Jefferson}

\author{
Leadership Committee Neurosurgery Student Interest Group
}

Jefferson Medical College

Follow this and additional works at: https://jdc.jefferson.edu/jhnj

Part of the Neurology Commons

Let us know how access to this document benefits you

\section{Recommended Citation}

Neurosurgery Student Interest Group, Leadership Committee (2012) "Undergraduate Neurosurgical Learning Opportunities at Jefferson," JHN Journal: Vol. 7 : Iss. 1 , Article 5.

DOI: https://doi.org/10.29046/JHNJ.007.1.004

Available at: https://jdc.jefferson.edu/jhnj/vol7/iss1/5

This Article is brought to you for free and open access by the Jefferson Digital Commons. The Jefferson Digital Commons is a service of Thomas Jefferson University's Center for Teaching and Learning (CTL). The Commons is a showcase for Jefferson books and journals, peer-reviewed scholarly publications, unique historical collections from the University archives, and teaching tools. The Jefferson Digital Commons allows researchers and interested readers anywhere in the world to learn about and keep up to date with Jefferson scholarship. This article has been accepted for inclusion in JHN Journal by an authorized administrator of the Jefferson Digital Commons. For more information, please contact: JeffersonDigitalCommons@jefferson.edu. 


\section{Undergraduate Neurosurgical Learning Opportunities at Jefferson}

Leadership Committee, Neurosurgery Student Interest Group, Jefferson Medical College ${ }^{1}$

'Jefferson Medical College, Philadelphia, Pennsylvania
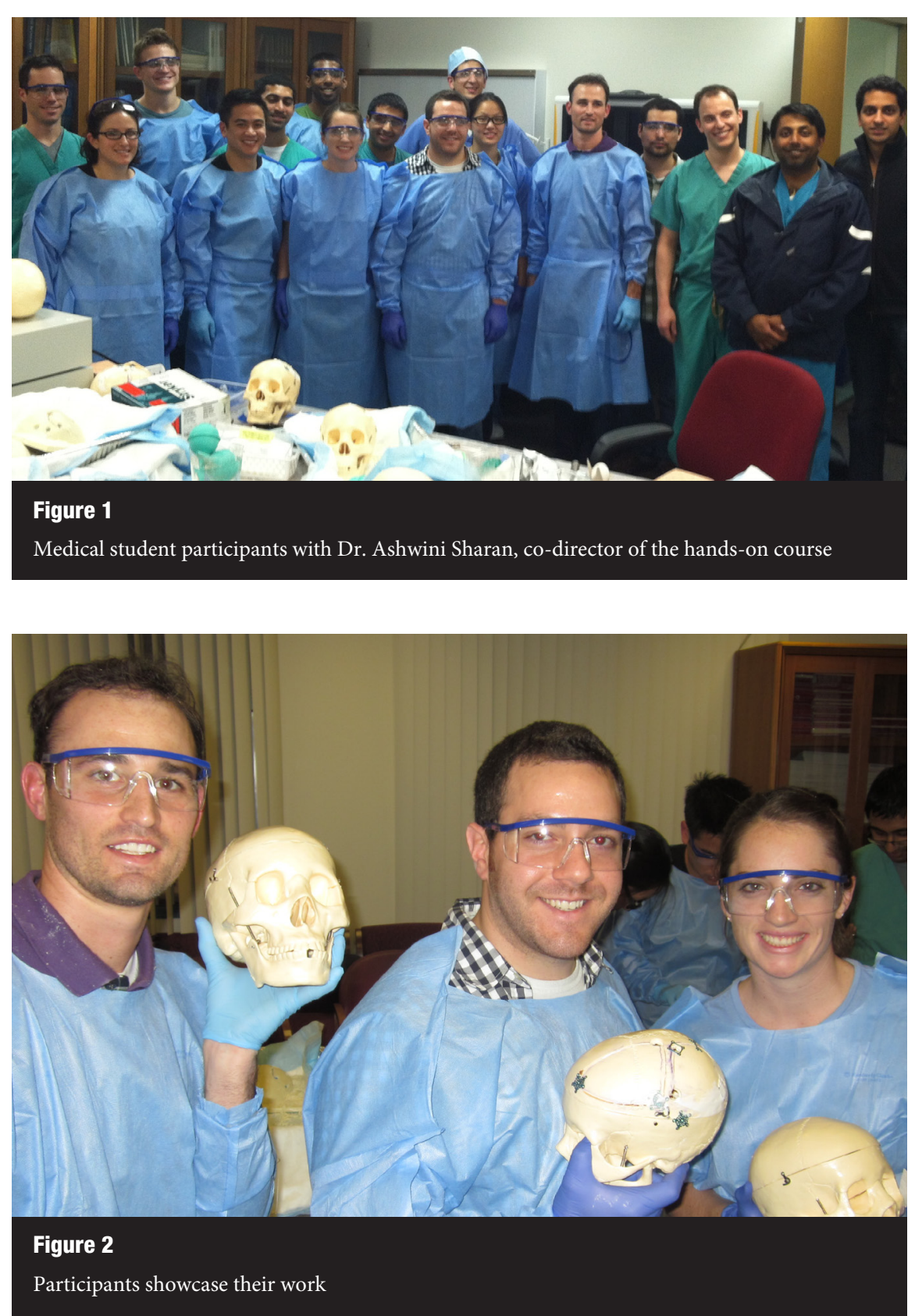

On the evening of November 29, 2011, Jefferson's Neurosurgery Interest Group (NSIG) hosted fourteen Jefferson Medical
College students for a technical course entitled College students for a technical course entitled
"Foundations in Neurosurgery" taught by Dr. Ashwini Sharan, Associate Professor of Neurosurgery and Director of the Division
of Functional Neurosurgery, and Dr. Joshua Heller, Assistant Professor of Neurosurgery at Thomas Jefferson University Hospital. Additional instructors included Jefferson neurosurgery residents Rohan Chitale (PGY5), (PGY2) Stryker MedED provided equipment models, and instructors Ryan Dugan and Devin Opdendyk (Figure 1).

Dr. Sharan began the course by describing basic principles of neurosurgical pathology, intracranial pressure, clinical decision-making, and assessment tools such as the Glasgow Coma Dr.Sharan identified relevant anatomical landmarks used for defining the borders of a skull flap and addressed various surgical techniques to treat intracranial bleeding as well as strate-
gies for creating Burr holes, craniotomies, and Students practiced many of these techniques on skull models. After learning principles of flap, they created burr holes using two different kinds of drill bits, a clutch-operated bit and an acorn bit. Students used the craniotome to connect burr holes and remove bone flaps, and
learned to re-attach bone flaps using plates and learned to re-attach bone laps using plates While students worked, Dr. Heller presented second lecture using preoperative imaging from hemorrhage secondary to cranial trauma to correlate clinical management. Using the Socratic method, Dr. Heller guided students though decle and proper craniects Glasgow Coma placement. Directly following his presentation students practiced creating a cranial bone flap on skull models, as if treating the patient presented. This interactive teaching and hands-on
approach helped students connect image-based planning with surgical performance. Students also praticed suturing Diram Finally, students participated in an egg-drilling outer shell off of an egg without puncturing the underlying membrane and breaking into the yolk. This exercise forced students to consider the meticulous and delicate skill a surgeo must employ to manipulate fragile anatomical
structures.

The course was the first of its kind at Jefferson and was well attended by 1 st, 2 nd, and 3rd-year ing, class of 2014, reflected that "The idea of using a power drill to slowly shave away bon just inches from someone s brain seems daunt-

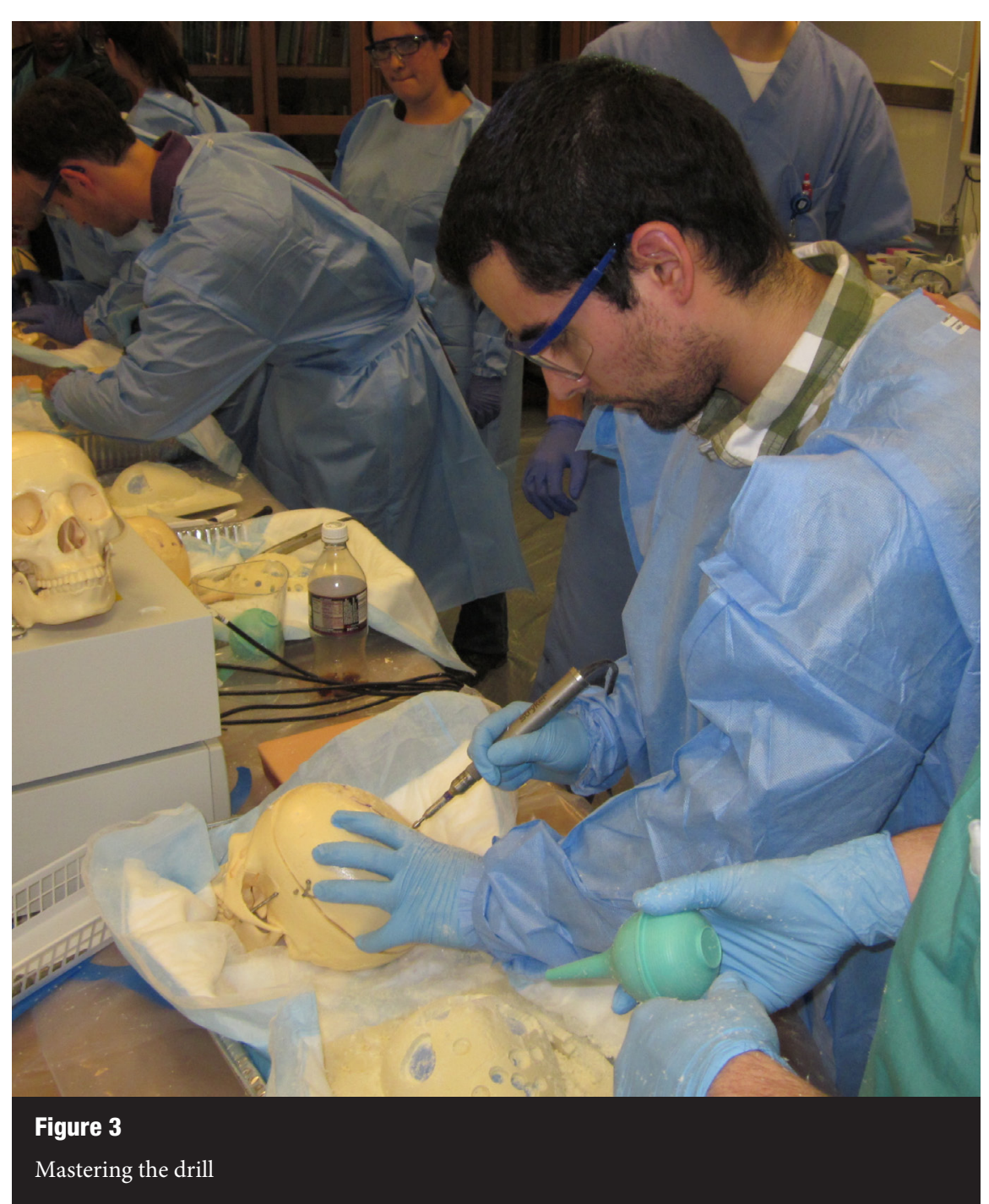

and get hands-on experience made the idea of 2014, said, "After watching drilling done in the operating room so many times, it was a lot of fun to finally get to perform similar procedures myself. The course granted studentsinvaluable neurosurgery rotations.

The Foudations of Neurosurgery course supported the overall mission of NSIG, a student-run group created in 2010, to further medical student knowledge of neurosurgical procedures and to provide opportunities for pester attendings and residents. A similar hands-on becoming a neurosurgeon seem much more by Dr. Pascal Jabbour, Assistant Professor of another hand at Jefferson. NSIG plans to hos this spring.

The course also supported the Jefferson Neurosurgery Department's mission to educate future neurosurgeons and train future educators. It gave attending physicians the opportunity to inspire a new crop of interested medical stusame time it gave newrosurgery residents opportunity to share their wisdom with medical students and hone their teaching skills. Finally, the event speaks volumes about Stryke's commitment to education. While practical learning sessions for attending physicians and ical comp a to depece, ti is rare for a suredical student education.

We thank the Jefferson Department of Incorporated for making this event so successfull The NSIG Leadership Committee Benjamin Zussman '13 (President) Dave Penn '13 (Vice President) Nick Hermandez ' 13 MS3 Representente Alex Whiting ' 14 (MS2 Representative) Zach Senders ' 14 (Research Liaison) Naomi Sell '15 (MS1 Representative) Adam Olszewski '15 (MS1 Representative) 